\title{
Impacts of House Sizes, Appliance Ratings and Usage Patterns on Demand Response Applications: A Case-Based Study
}

\author{
Murat Kuzlu $^{1}$ - Manisa Pipattanasomporn ${ }^{1} \cdot$ Saifur Rahman $^{1}$
}

Received: 6 July 2015 / Revised: 16 October 2015 / Accepted: 17 October 2015 / Published online: 6 November 2015

(C) Springer Science+Business Media Singapore 2015

\begin{abstract}
A home energy management (HEM) system is an important element that potentially facilitates automated demand response (DR) participation for residential customers. This paper aims at analyzing the impact of different house sizes, appliance ratings and usage patterns on residential DR implementation based on a set of predefined DR strategies. In particular, several simulation studies are conducted to demonstrate how an HEM system performs differently when implemented in households that have different characteristics. Results show that houses of different sizes, appliance ratings and usage patterns have different impacts on customers' comfort level violation, and determine the levels of DR that can be implemented.
\end{abstract}

Keywords Demand response (DR) - Home energy management (HEM) - Appliance ratings · Usage patterns and smart grid

\section{Introduction}

Frequent stress conditions in electric power systems are more prevalent in today's environment. This is partly due to an ever-increasing end-use electricity demand [1]. Such stress conditions may lead to electricity blackouts involving cascading outages of transmission lines. Demand Response

Murat Kuzlu

mkuzlu@vt.edu

Manisa Pipattanasomporn

mpipatta@vt.edu

Saifur Rahman

srahman@vt.edu

1 Department of Electrical and Computer Engineering, Virginia Tech - Advanced Research Institute, Arlington, USA
(DR) can play a crucial role in mitigating system stress conditions by selectively curtailing system loads. Therefore, electricity supply continuity during peak demand periods can be ensured [2,3].

$\mathrm{DR}$, in a broad sense, refers to an active participation by retail customers to adjust their electricity consumption in response to electricity price or load control signals from a utility [4]. In general, there are three types of DR implementation: manual, semi-automated and fully-automated [5]. The fully-automated control can be achieved with the help of a Home Energy Management (HEM) system, and is the most popular automation type that does not involve human intervention. The HEM system is designed to monitor and control the operation of in-home appliances, and providing load shifting and shedding as necessary according to customer preferences. The operation of an HEM system can be initiated by a DR signal sent by a local utility.

In recent years, different DR algorithms and models were presented depending on load types and DR program requirements. In [6] authors propose a DR strategy to encourage plug-in electric vehicle (PHEV) users to participate in DR programs. In [7] authors propose an optimization model implemented using IBM ILOG CPLEX to minimize the operation energy costs for a residential microgrid. It also shows how distributed energy sources, storage units, thermoelectric units, and loads operate in response to changes in electricity prices. In [8-10], authors present load-scheduling algorithms, which minimize household energy consumption or electricity bills. Different HEM system solutions describing various power management services were also proposed in [11-15]. Most of these work focus on monitoring and control of all appliances, including refrigerators, coffee makers, lighting and other plug loads-which may not be suitable for participation in DR programs. This is because some of these loads have low power consumption and most of these 
loads, if controlled, will cause inconvenience and discomfort to homeowners. In our previous paper [16], an intelligent HEM algorithm was proposed to manage power-intensive appliances. We showcase the effectiveness of the proposed algorithm to perform DR with actual hardware implementation in [17].

In this paper, our previously developed HEM algorithm is used as a basis to analyze the impact of automated DR on households of different house sizes, appliance ratings and usage patterns. Based on a thorough literature search, this topic has not been fully addressed. There are still many ongoing researches on HEM systems as it is not clear about the ability of a household to perform load curtailment given a number of parameters involved, such as appliance ratings, customer behaviors, house sizes, number of people in a house and type of appliances. This issue is further complicated by customer priority and comfort level requirement. Due to the reason above, several case studies are performed to provide an understanding of how an HEM performs differently for a DR implementation in households of different sizes, appliance ratings and usage patterns. This can benefit electric utilities in designing appropriate DR programs and academia/ industry researchers in designing HEM systems for auto-DR applications.

\section{The DR Concept and The HEM Algorithm}

An HEM is a vital piece that allows full customer participation in a DR program. This section briefly describes our DR concept and its associated HEM algorithm.

\section{The DR Concept}

In our DR concept, an HEM system comprises: an HEM unit, a group of sensors/controllers, and a gateway. See Fig. 1.

The HEM unit is embedded with an intelligent DR algorithm. It collects information about the total house power consumption, as well as the power consumption and the status of selected appliances. A group of sensors and controllers, e.g., smart plug, provides electrical measurements and status of selected appliances. A gateway, e.g., smart meter, provides a secure connection between the HEM unit and the utility. The HEM unit can be informed of a DR event according to a signal received from a utility via the gateway.

A DR event can be initiated by a signal from a utility, which can be in various forms, e.g., time-varying price signals and load curtailment requests. For our study, it is assumed that the DR event signal is based on the latter. Our DR concept aims at managing and controlling only power-intensive appliances. These are central air conditioners, electric clothes dryers, electric water heaters, and electric vehicles. These appliances, if controlled, will contribute

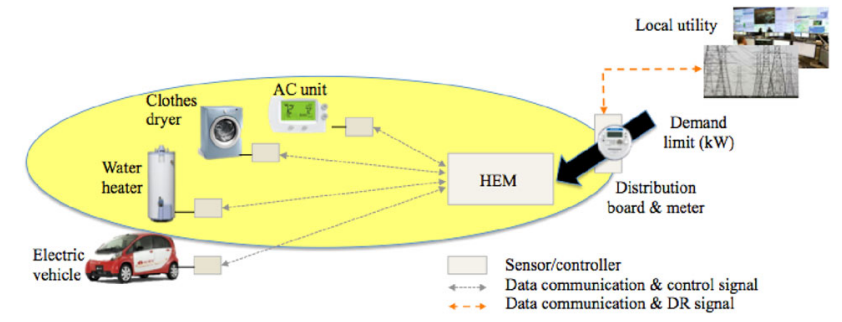

Fig. 1 The HEM system architecture

significantly to the reduction of overall household power consumption.

\section{The HEM Algorithm}

To analyze the impact of different house sizes, appliance ratings and usage patterns on residential DR implementation, the HEM algorithm presented in $[16,17]$ is employed. This HEM algorithm guarantees the total household power consumption below a certain demand limit level (kW), e.g., $8 \mathrm{~kW}$, during a DR event period, e.g., 5:00-10:00 PM, while satisfying preset customer preferences. See Eq. (1). This gives a homeowner the freedom to choose what loads to manage and for how long.

$P_{\text {total }}=P_{0}+\sum_{i=1}^{n} P_{i} \leq P_{D L}$

where $P_{\text {total }}$ : The total household power consumption; $P_{0}$ : The power consumption of critical loads; $P_{D L}$ : The demand limit; $P_{i}$ : The power consumption of appliance $i ; n$ : Total number of appliances in a house; $i$ : The appliance index ( $i=$ $1,2, \ldots, n)$.

This approach presents a new DR paradigm that differs from direct load control programs being implemented in several electric utilities' service areas.

The overview of the HEM algorithm and its decisionmaking process are illustrated in Fig. 2.

The algorithm can be explained as follows: First, all data are gathered from appliances through appliance monitoring and control units (i.e., appliance status and their power ratings), temperature sensors (i.e., water and room temperatures) and users (i.e., load priority and comfort settings). Once a DR signal is received from a local utility or a demand aggregator, the HEM unit calculates the total household power consumption based on the data gathered on appliances' status and their power consumption. The HEM unit compares the total household power consumption $\left(P_{\text {total }}\right)$ with the demand limit $\left(P_{D L}\right)$. It then decides the operating status of each appliance, i.e., $A r S_{A P P, i}$, in the next time step based on load priority and comfort level settings. Detailed explanation of this algorithm can be found in [17]. 


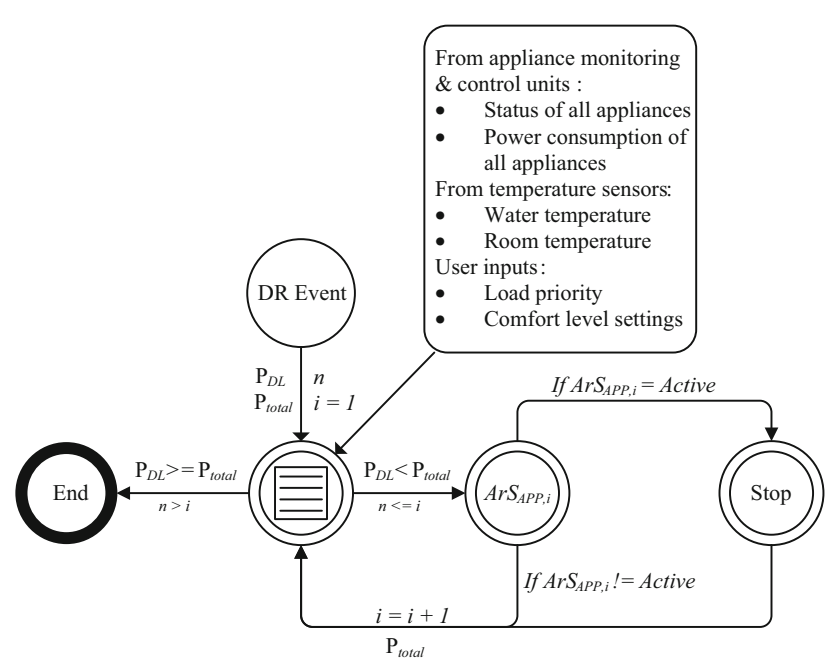

Fig. 2 Overview of the HEM algorithm and its decision-making process

Customer preferences comprise:

1. Load priority setting The load priority setting allows a homeowner to specify the importance of appliance in relative to each other. For example, a homeowner may select an air conditioner (AC) to have higher priority than a water heater (WH), a clothes dryer (CD) and an electric vehicle $(\mathrm{EV})$. In this case, the priority setting is: $\mathrm{AC}>\mathrm{WH}>\mathrm{CD}>\mathrm{EV}$.

2. Specific preference for each load type For an AC unit, such parameters include the room temperature set point $\left({ }^{\circ} \mathrm{F}\right)$ and dead band $\left({ }^{\circ} \mathrm{F}\right)$. For a WH unit, these include the hot water temperature set point $\left({ }^{\circ} \mathrm{F}\right)$ and the temperature tolerance $\left({ }^{\circ} \mathrm{F}\right)$. For a clothes dryer unit, a homeowner can specify the minimum heating coils ON time, the maximum heating coils OFF time, and the time when the clothes dryer must finish its job. The minimum heating coils ON time is to ensure that the clothes dryer can operate for a specified duration before it can be turned OFF by the HEM. The maximum heating coils OFF time is to ensure that the clothes dryer does not get controlled for longer than a specified period. For an EV, a homeowner can specify the time when the EV must finish charging.
An example of customer preference settings is shown in Table 1.

\section{Case Study Description}

This section describes case studies and their assumptions.

\section{House Size Assumptions}

For a comparison purpose, three house sizes are considered: 1500, 2500 and 4500 sqft. The 1500 sqft size represents a relatively small house in the U.S.; the 2500sqft size represents an average American house size; and the 4500sqft size represents a relatively large house. Table 2 summarizes parameters of these houses under study. These include house square footage; areas of floor, ceiling, wall and window (i.e., $A_{\text {floor }}, A_{\text {ceiling }}, A_{\text {wall }}, A_{\text {window }}$ ); their heat resistance (i.e., $R_{\text {wall }}, R_{\text {ceiling }}, R_{\text {window }}$ ), and number of people in the house.

In this study it is assumed that household occupants are 2, 3 and 5 for 1500, 2500 and 4500 sqft houses, respectively. This is based on the assumption that the house size tends to increase with the number of occupants. The number of occupants affects the internal heat gain and the amount of hot water usage. Internal heat gain is used by HVAC model. Higher internal heat gain causes the rise in the room temperature, and higher amount of hot water usage causes longer water heater operation. These factors are taken into account in this study.

\section{Appliance Quantity and Rating Assumptions}

In this study, the impact of various appliance ownerships and ratings on DR implementation is of interest. Based on a survey of three houses in the Washington DC metro area, it is assumed that the 1500 and 2500 sqft houses have one AC unit, while the 4500 house has two AC units. Each house is assumed to have one electric water heater unit, one electric clothes dryer, and an electric vehicle. Table 3 summarizes the
Table 1 Example customer comfort preference settings

\begin{tabular}{llll}
\hline Appliance & Priority & Time of operation & Customer preference \\
\hline Air conditioner (AC) & 1 & All day & $\begin{array}{l}\text { Room temperature set point: } 76^{\circ} \mathrm{F} \\
\text { Dead band: } \pm 2^{\circ} \mathrm{F}\end{array}$ \\
Water heater $(\mathrm{WH})$ & 2 & All day & $\begin{array}{l}\text { Hot water temp set point: } 120^{\circ} \mathrm{F} \\
\text { Temperature tolerance: } 10^{\circ} \mathrm{F}\end{array}$ \\
& 3 & Before 12:00 AM & $\begin{array}{l}\text { Minimum ON time: } 30 \text { min } \\
\text { Clothes dryer }(\mathrm{CD})\end{array}$ \\
& & & $\begin{array}{l}\text { Maximum OFF time: } 30 \mathrm{~min} \\
\text { Finish its job by } 12: 00 \mathrm{AM}\end{array}$ \\
Electric vehicle $(\mathrm{EV})$ & 4 & Finish its job by $6: 00 \mathrm{AM}$
\end{tabular}


Table 2 Parameters of three houses under study

\begin{tabular}{llll}
\hline Parameter & 1500 sqft house & 2500 sqft house & 4500 sqft house \\
\hline House size (sqft) & 1500 & $2000+500$ (basement) & $\begin{array}{l}\text { 1st floor: } 2000 \\
\text { 2nd floor: } 2500\end{array}$ \\
$\mathrm{~A}_{\text {floor }}, \mathrm{A}_{\text {ceiling }}, \mathrm{A}_{\text {wall }}, \mathrm{A}_{\text {window }}(\mathrm{sqft})$ & $1500,1500,1600,800$ & $2000,2000,2600,520$ & 1 st floor: $2000,2000,1800,900$ \\
& & & 2 nd floor: $2500,2500,2000,1000$ \\
$\mathrm{R}_{\text {wall }}, \mathrm{R}_{\text {ceiling }}, \mathrm{R}_{\text {window }}\left(\mathrm{ft}{ }^{2 * o} \mathrm{~F} /(\mathrm{btu} / \mathrm{h})\right)$ & $13,30,0.8$ & $13,30,0.8$ & $13,30,0.8$ \\
Number of people & 2 & 3 & 5
\end{tabular}

Table 3 Parameters of appliances and critical loads

\begin{tabular}{|c|c|c|c|}
\hline Parameter & 1500 sqft house & $2500 \mathrm{sqft}$ house & 4500 sqft house \\
\hline \multicolumn{4}{|l|}{ Air conditioner (AC) } \\
\hline Number of AC & 1 & 1 & 2 \\
\hline $\mathrm{AC}$ rating $(\mathrm{kW})$ & 1.9 & 2.6 & $\begin{array}{l}2.6 \text { (1st floor) } \\
3.4 \text { (2nd floor) }\end{array}$ \\
\hline AC capacity (BTU) & 24,000 & 30,000 & $\begin{array}{l}30,000 \text { (1st floor) } \\
34,000 \text { (2nd floor) }\end{array}$ \\
\hline \multicolumn{4}{|l|}{ Electric water heater (WH) } \\
\hline Number of WH & 1 & 1 & 1 \\
\hline WH rating $(\mathrm{kW})$ & 3.8 & 4.5 & 4.5 \\
\hline WH tank size (gallons) & 38 & 50 & 80 \\
\hline WH tank R value $\left(\mathrm{ft}^{2 * \circ} \mathrm{F} /(\mathrm{BTU} / \mathrm{h})\right)$ & 18 & 18 & 18 \\
\hline \multicolumn{4}{|l|}{ Electric clothes dryer (CD) } \\
\hline Number of CD & 1 & 1 & 1 \\
\hline $\mathrm{CD}$ rating $(\mathrm{kW})$ & $\begin{array}{l}2.9(0.2 \mathrm{~kW} \\
\text { motor; } 2.7 \mathrm{~kW} \\
\text { heating coil })\end{array}$ & $\begin{array}{l}4.0(0.3 \mathrm{~kW} \\
\text { motor; } 3.7 \mathrm{~kW} \\
\text { heating coil })\end{array}$ & $\begin{array}{l}4.9(0.35 \mathrm{~kW} \\
\text { motor; } 4.55 \mathrm{~kW} \\
\text { heating coil })\end{array}$ \\
\hline \multicolumn{4}{|l|}{ Electric vehicle (EV) } \\
\hline Number of EV & 1 & 1 & 1 \\
\hline EV rating $(\mathrm{kW})$ & 3.3 & 3.3 & $3.3[18]$ \\
\hline
\end{tabular}

quantity of appliances in each house, their $\mathrm{kW}$ ratings, and other parameters, such as BTU capacity of AC units, water heater tank sizes and $\mathrm{R}$ values. The EV rating is based on the recommended charge rate of Chevy Volt [18], which is 3.3 $\mathrm{kW}$.

\section{Customer Preference Assumptions}

For load priority, it is assumed that all houses select AC as the highest priority load during a hot summer day. This is followed by water heaters, clothes dryers and electric vehicles. For the 4500 sqft house, it is assumed that AC1 has lower priority than AC2. See Table 4.

Since our analysis focuses on the impact of different house sizes, appliance ownership and ratings on DR implementation, comfort level settings and appliance usage patterns are kept the same for all houses under study. That is, for $\mathrm{AC}$, room temperature set points for all houses are set at $76^{\circ} \mathrm{F} \pm 2{ }^{\circ} \mathrm{F}$. For ambient temperature, a summer day in July 2012 is used as a basis of all case studies. Since all three houses are located within the same vicinity, the same ambient temperature is used and is obtained from [19]. For WH, the hot water temperature set point is set between $110-120^{\circ} \mathrm{F}$. While the amount of hot water drawn varies according to the number of people living in the house, the hot water drawn profile used in this study is the same from all houses and is taken from IEA for a typical summer day [20]. For CD, each clothes dryer starts its operation at 6:30 PM and should finish its job by midnight. Lastly, each EV is plugged in at 5:00 PM and should finish its charging by 6:00 AM.

\section{Critical Load Assumptions}

Critical loads are to be served at all times. Data used for critical loads are real-world measurement data in 1-min intervals from the 1500, 2500 and 4500 sqft houses under study. 
Table 4 Load priority, usage and comfort level assumptions

\begin{tabular}{|c|c|c|c|}
\hline Parameter & 1500 sqft house & 2500 sqft house & 4500 sqft house \\
\hline Load priority & $\mathrm{AC}>\mathrm{WH}>\mathrm{CD}>\mathrm{EV}$ & $\mathrm{AC}>\mathrm{WH}>\mathrm{CD}>\mathrm{EV}$ & $\mathrm{AC} 2>\mathrm{AC} 1>\mathrm{WH}>\mathrm{CD}>\mathrm{EV}$ \\
\hline $\mathrm{AC}$ & \multicolumn{2}{|c|}{ AC temperature set point: $76 \pm 2{ }^{\circ} \mathrm{F}$} & \\
\hline WH & \multicolumn{3}{|c|}{ WH temperature set point: $110-120^{\circ} \mathrm{F}$} \\
\hline $\mathrm{CD}$ & $\begin{array}{l}\text { CD start time: } 6: 30 \mathrm{P} \\
\mathrm{CD} \text { operation duratio } \\
\mathrm{CD} \text { complete time: } \mathrm{B} \\
\text { Maximum heating co } \\
\text { Minimum heating co }\end{array}$ & $\begin{array}{l}\text { mins } \\
\text { midnight } \\
\text { F time: } 30 \text { mins } \\
\text { time: } 30 \text { mins }\end{array}$ & \\
\hline EV & $\begin{array}{l}\text { EV charge time: } 5: 00 \\
\text { EV charge duration: } \\
\text { EV complete time: B }\end{array}$ & $\begin{array}{l}\text { ins } \\
\text { 6:00 AM }\end{array}$ & \\
\hline
\end{tabular}

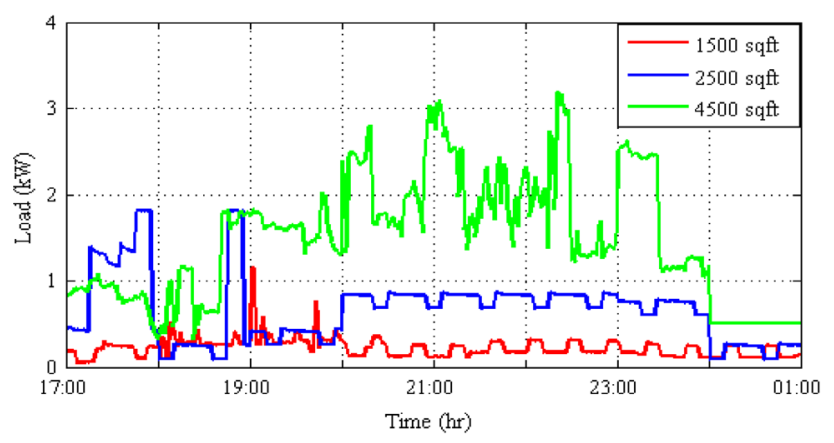

Fig. 3 Critical load profiles of 1500, 2500 and 4500 sqft houses

All measurements were performed with the same equipment, i.e., TED500 in-home electricity monitor [21]. Figure 3 shows critical load power consumption of these three houses between 5:00 PM and 01:00 AM. These loads account for lights, computer equipment, a refrigerator, a teakettle, a microwave and an electric oven.

From Fig. 3, critical load data for the 1500 sqft house vary between 0.1 and $1.2 \mathrm{~kW}$; that for the 2500 sqft house vary between 0.3 and $1.8 \mathrm{~kW}$; and that for the 4500 sqft house vary between 0.5 and $3.1 \mathrm{~kW}$. The $1500 \mathrm{sqft}$ and the 2500 sqft houses have lower critical load consumption than that of the $4500 \mathrm{sqft}$ house. This is generally because these houses have less square footage and fewer people in the house, thus fewer units of electrical appliances.

\section{Load Profiles}

For an illustrative purpose, Fig. 4 shows total house load profiles of three houses under study when they have the same usage patterns of power-intensive appliances. Note that house parameters, appliance ratings and customers' comfort preferences are listed in Tables 2, 3 and 4.

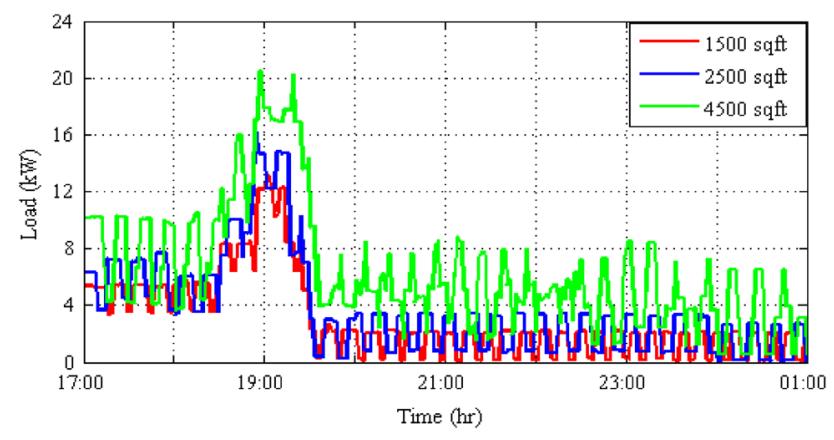

Fig. 4 Household load profiles of 1500, 2500 and 4500 sqft houses

It can be seen that peak loads of different house sizes can vary from $13.0 \mathrm{~kW}$ in the $1500 \mathrm{sqft}$ house to $20.5 \mathrm{~kW}$ in the 4500 sqft house. In general, smaller houses have a lower peak demand than bigger houses. This is because smaller houses generally have fewer appliances of lower $\mathrm{kW}$ ratings.

\section{Demand Limit Assumptions}

It is assumed that a DR event occurs between 5:00 PM and 10:00 PM as peak demand from residential customers usually occur during this period. During a DR event, each house must maintain its peak demand below a certain value. Demand curtailment requests are set at 25, 50 and $75 \%$ reductions from the original peak demand. The $75 \%$ demand reduction is an extreme case intended to showcase how such a high load curtailment request can impact customer comfort level.

\section{Results of DR Implementation for the 1500, 2500 and 4500 sqft Houses}

This section presents case study results and analyzes how the HEM algorithm performs differently for different houses that are of different load profiles, house sizes, appliance ownership and ratings. 


\section{0 sqft House}

Figure 5 illustrates the performance of the proposed HEM algorithm in managing power-intensive appliances in the 1500 sqft house. The figure displays the total household power consumption between 5:00 PM and 1:00 AM in a noDR event case in Fig. 5a; and with DR events from 5:00 PM to $10: 00 \mathrm{PM}$ at 25,50 and $75 \%$ peak load reduction requests in Fig. 5b-d, respectively. Note that while the DR event ends at 10:00 PM, the demand shifting and compensation period ends by 1:00 AM.

\section{Case 1-No DR}

In the base case scenario with no demand limit as shown in Fig. 5a, the AC unit cycles ON and OFF to maintain the room temperature within the preset comfort level, i.e., 74$78^{\circ} \mathrm{F}$. There are some hot water drawn events between 6:50 PM and 7:00 PM. The large water draw event makes the hot water temperature drops rapidly below the preset threshold. The water heater then operates to bring the water temperature back within the preset comfort range. The preset water temperature comfort level $\left(110-120^{\circ} \mathrm{F}\right)$ can be inherently violated due to a large water draw event. The clothes dryer starts its operation at 6:30 PM. The EV is plugged in as soon as the homeowner arrives home at 5:00 PM. The critical load power consumption for this house, as shown in Fig. 3, varies every minute with an average value of $0.70 \mathrm{~kW}$ during the DR event. As shown, the total power consumption of this house increases to about $13 \mathrm{~kW}$ (AC $1.9 \mathrm{~kW}+\mathrm{WH} 3.8 \mathrm{~kW}+\mathrm{CD}$ $2.9 \mathrm{~kW}+\mathrm{EV} 3.3 \mathrm{~kW}+$ critical loads) between 06:50-7:15 PM.

Case $2-w / D R$ at $25 \%$ peak reduction $(9.8 \mathrm{~kW}$ demand limit)

As shown in Fig. 5b, with the demand limit of about 9.8 $\mathrm{kW}$ at $25 \%$ peak load curtailment request, the load shifting/compensation period occurs only between 6:50 PM and 7:42 PM. This is because, at the beginning of this period with a high hot water drawn event at 6:50 PM, the AC unit (1.9 $\mathrm{kW})$ can operate together with the WH $(3.8 \mathrm{~kW})$ and either the $\mathrm{CD}(2.9 \mathrm{~kW})$ or the EV $(3.3 \mathrm{~kW})$-while critical loads must be served at all time. In this scenario, the clothes dryer minimum $\mathrm{ON}$ time is specified at $30 \mathrm{~min}$. Note that when the clothes dryer gets controlled, the motor part $(0.2 \mathrm{~kW})$ keeps on running, while the heating coils $(2.7 \mathrm{~kW})$ are shut off. The overall HEM algorithm results in a 2-min delay of the $\mathrm{CD}$ complete time and a 17-min delay of the EV charging
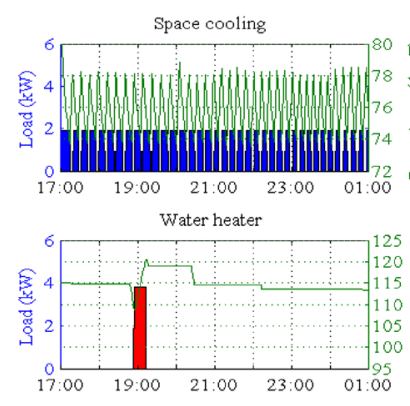

Clothes dryer
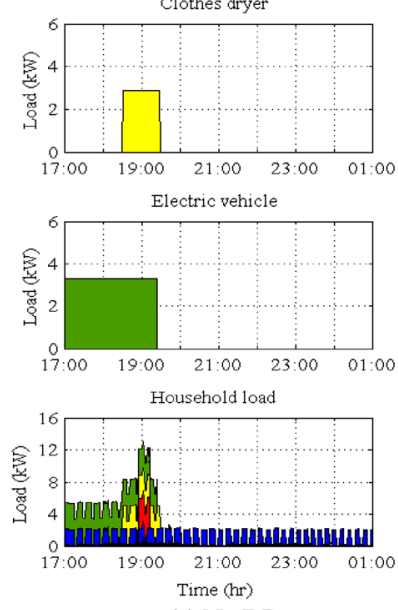

(a) No DR
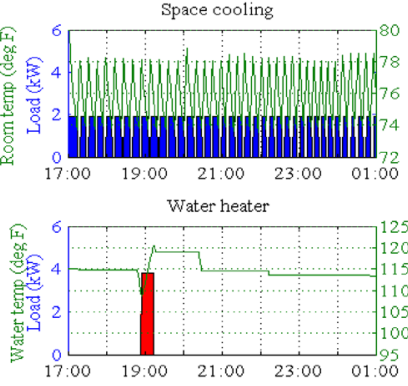

Clothes dryer

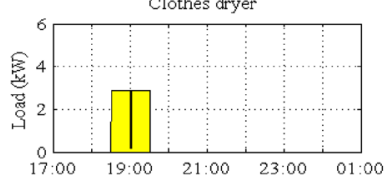

Electric vehicle
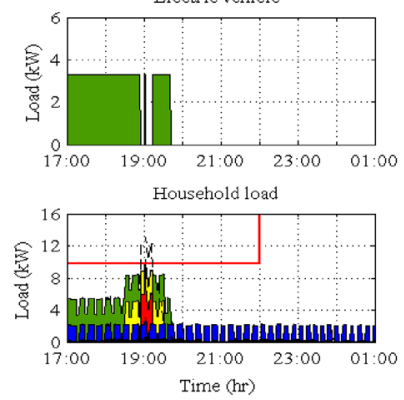

(b) $25 \%$ peak reduction
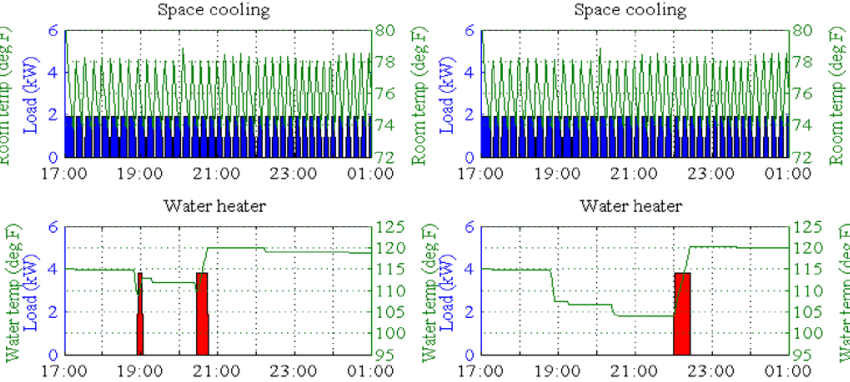

Clothes dryer

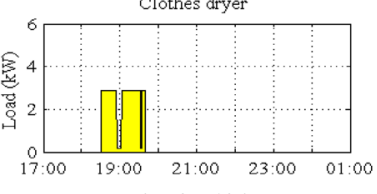

Electric vehicle
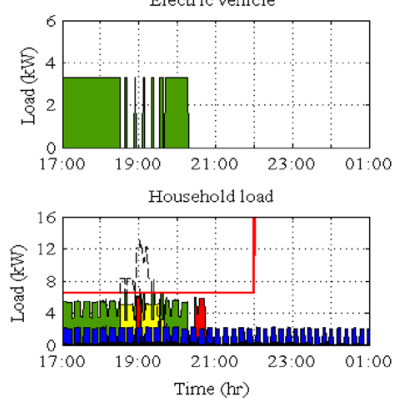

(c) $50 \%$ peak reduction

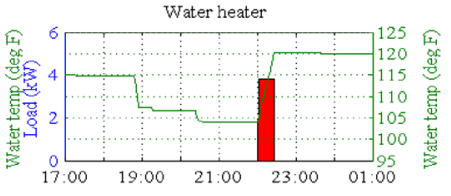

Clothes dryer

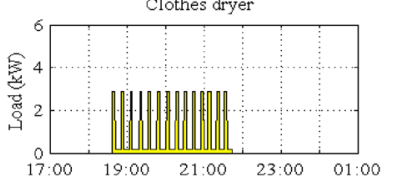

Electric vehicle
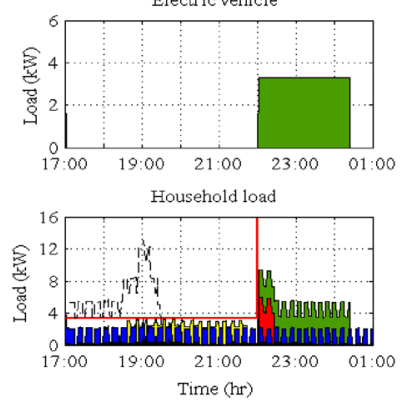

(d) $75 \%$ peak reduction

Room/water temperature

Fig. 5 Power consumption of individual appliances (AC, WH, CD and EV) and total household load profiles for the 1500 sqft house between 5:00 PM and 1:00 AM: (a) no DR; (b) w/DR at 25\% load curtailment request; (c) w/DR at $50 \%$ load curtailment request; and (d) w/DR at $75 \%$ load curtailment request 
complete time. The comfort level violation and load compensation time for all cases are summarized in Table 5 .

Case $3-w / D R$ at $50 \%$ peak reduction $(6.5 \mathrm{~kW}$ demand limit)

As shown in Fig. 5c, at the demand limit of about $6.5 \mathrm{~kW}$, the load shifting/compensation period starts from 6:50 PM to around 08:45 PM. Similar to Case 2, as the high hot water drawn event starts at 6:50 PM, the AC unit $(1.9 \mathrm{~kW})$ cannot operate with the $\mathrm{WH}(3.8 \mathrm{~kW})$ during high critical load, e.g., around 1.5 kW between 7:02 PM and 7:05 PM. Therefore, the $\mathrm{WH}$ is turned OFF at that time, and it starts at 8:27 PM when another hot water drawn event occurs. This scenario causes a low hot water temperature violation. When the CD $(2.9 \mathrm{~kW})$ starts, the EV $(3.3 \mathrm{~kW})$ can cycle with the AC $(1.9$ $\mathrm{kW}$ ) between 06:30 PM and 07:40 PM. Both CD and EV are deferred as soon as the WH starts around 06:30 PM. This results in a 10-min deferral on the $\mathrm{CD}$ job; and a 53-mins delay of the EV charge complete time.

Case 4-w/ DR at $75 \%$ peak reduction $(3.3 \mathrm{~kW}$ demand limit)

At the $3.3 \mathrm{~kW}$ demand limit, the critical load can operate together with the $\mathrm{AC}(1.9 \mathrm{~kW})$, and the $\mathrm{CD}(2.9 \mathrm{~kW})$ can only cycle with AC operation. The WH and the EV must wait until after the DR event ends at 10:00 PM to start their operation. Hence, the load shifting/compensation period continues until 00:24 AM. This scenario causes a 135-min delay of the CD job; a hot water temperature violation (i.e., the hot water temperature goes down to $104^{\circ} \mathrm{F}$ ); and a 300-min delay of the EV charge complete time. Notice the total household power consumption reaches $9.3 \mathrm{~kW}$ during an off-peak period after the DR event ends. See Fig. 5d.

\section{0 sqft House}

Figure 6 shows household load profiles of the 2500 sqft house when a DR event was imposed between 5:00 PM and 10:00 $\mathrm{PM}$ at 25, 50 and $75 \%$ reductions from its original peak demand. Comfort level settings and appliance usage patterns are assumed to be the same as those for the 1500 sqft house, while appliance ratings $(\mathrm{kW})$ change.

In the base case scenario with no demand limit as shown in Fig. 6a, the total power consumption of this house increases to about $16.2 \mathrm{~kW}$ (AC $2.6 \mathrm{~kW}+\mathrm{WH} 4.0 \mathrm{~kW}+\mathrm{CD} 4.5 \mathrm{~kW}+\mathrm{EV}$ $3.3 \mathrm{~kW}+$ critical loads) between 06:50-7:20 PM. With a load curtailment request, customer violation and load compensation occur during the DR event. The effect starts with the EV load, which is of the lowest priority. Brief load compensation times occur at the $25 \%$ peak load reduction request, i.e., 3-min delay of the $\mathrm{EV}$ charge complete time and 12-min delay of the clothes drying job. See Fig. 6b. Higher peak load reduction requests cause more violation and compensation, particularly to low priority loads. See Fig. 6c and d. Customer violations for high priority loads occur with the $75 \%$ peak load reduction request, as the $\mathrm{AC}$ cannot operate together with critical loads around 5:30-7:00 PM. In this caseFig. 6d, a low demand limit level also leads to the high offpeak demand due to high load compensation after a DR event ends.

\section{0 sqft House}

As shown in Fig. 7, a DR event was imposed between 5:00 PM and 10:00 PM for a 4500 sqft house. Customer preference assumptions, including load priority, appliance usage and comfort level settings are shown in Table 4. Appliances in this house have higher $\mathrm{kW}$ rating than the 1500 sqft and the 2500 sqft houses, with two air conditioners.

In the base case scenario with no demand limit in Fig. 7a, the total power consumption of this house is about 20.5 $\mathrm{kW}(\mathrm{AC} 12.6 \mathrm{~kW}+\mathrm{AC} 23.4 \mathrm{~kW}+\mathrm{WH} 4.5 \mathrm{~kW}+\mathrm{CD}$ $4.9 \mathrm{~kW}+$ EV $3.3 \mathrm{~kW}+$ critical loads) between 06:50 7:20 PM. During a request to reduce the peak demand, the EV load, which has the lowest priority, is the first to be shifted. This scenario results in a 42-min delay of the EV charging complete time with the $25 \%$ peak load reduction request. See Fig. 7b. Higher load reduction requests, i.e., lower demand limit levels, cause more violation and compensation. For example, the clothes drying job is deferred for 35 and 210 mins, the EV charging is deferred for 109 and 295 mins with 50 and $75 \%$ demand reduction requests, respectively. See Fig. 7c and d. A low demand limit may also cause customer violations for high priority loads. The room temperature increases to $85.4^{\circ} \mathrm{F}$ and hot water temperature decreases to $102^{\circ} \mathrm{F}$ with the $75 \%$ demand reduction request. As expected, high off-peak demand is experienced after a DR event ends at a high demand reduction request. See Fig. 7 d.

\section{Comparison of DR Implementation on Houses of Different Sizes and Appliance Ratings}

In this study, different DR case studies are simulated for three different house sizes as discussed earlier. Differences between these houses are: critical load profiles, number of appliances and appliance ratings. Table 5 summarizes comfort level violation and load compensation levels for these case studies at different demand limit levels. Generally, a higher load curtailment request will lead to more customer violation and load compensation.

Additionally, the following observations can be made:

Observation 1 A smaller house (house with lower appliance ratings, fewer number of appliances and fewer number of occupants) tends to offer more flexibility to perform DR than a bigger house, as less consumer comfort violation is experienced during a DR event. 


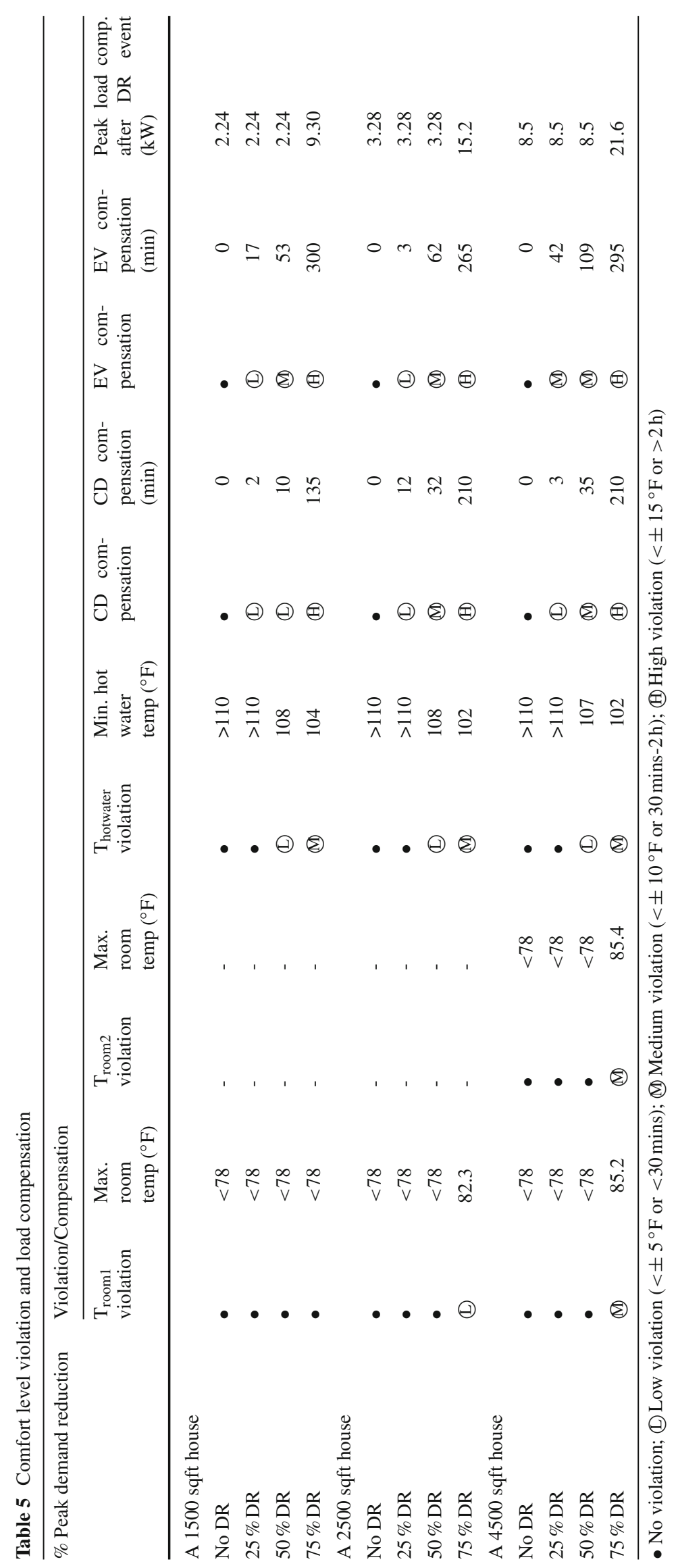




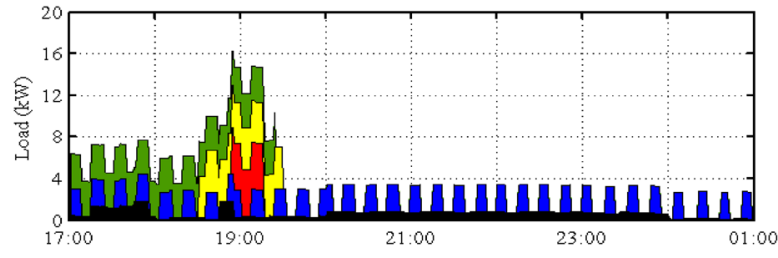

(a) - Time (hr)

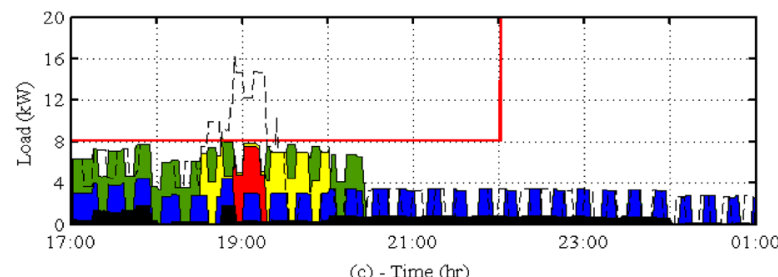

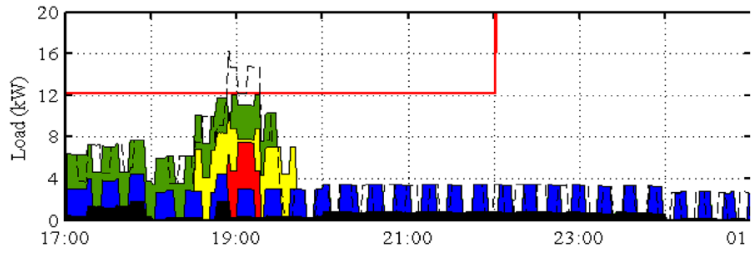

(b) - Time (hr)

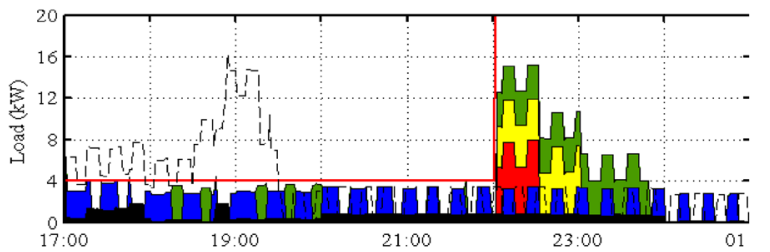

(d) - Time (hr)

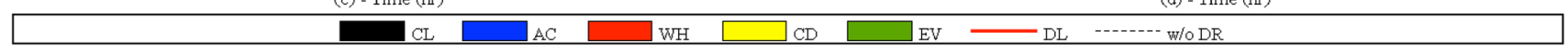

Fig. 6 Total household load profiles of the 2500 sqft house with information of all four appliances (WH, AC, CD, EV) between 5:00 PM and 1:00 AM: (a) no DR; (b) w/DR at $25 \%$ load curtailment request; (c) w/DR at $50 \%$ load curtailment request; and (d) w/DR at $75 \%$ load curtailment request
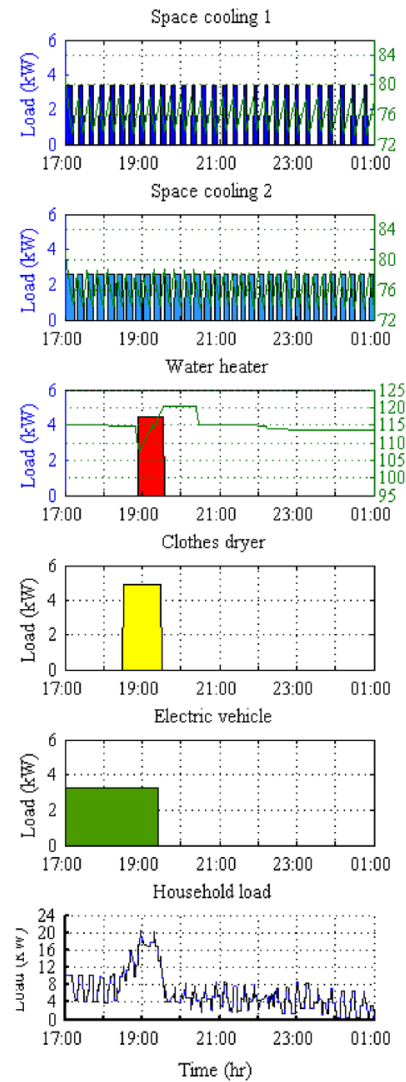

(a) No DR
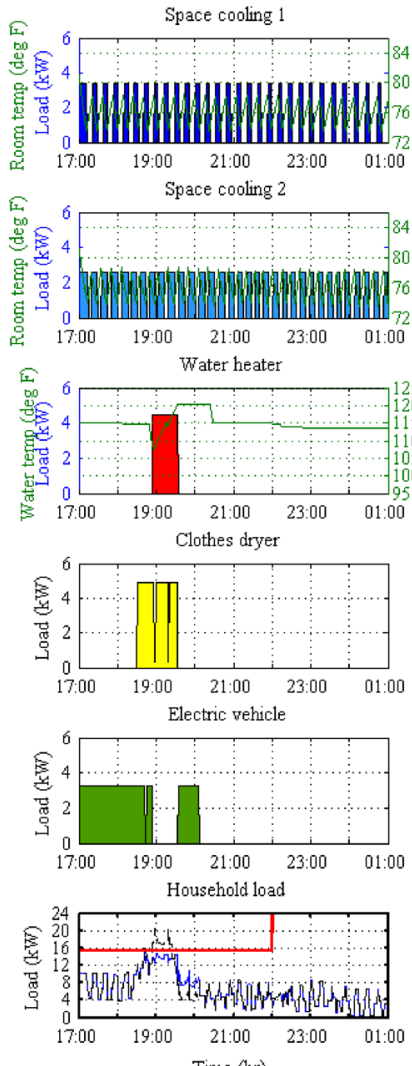

(b) $25 \%$ peak reduction
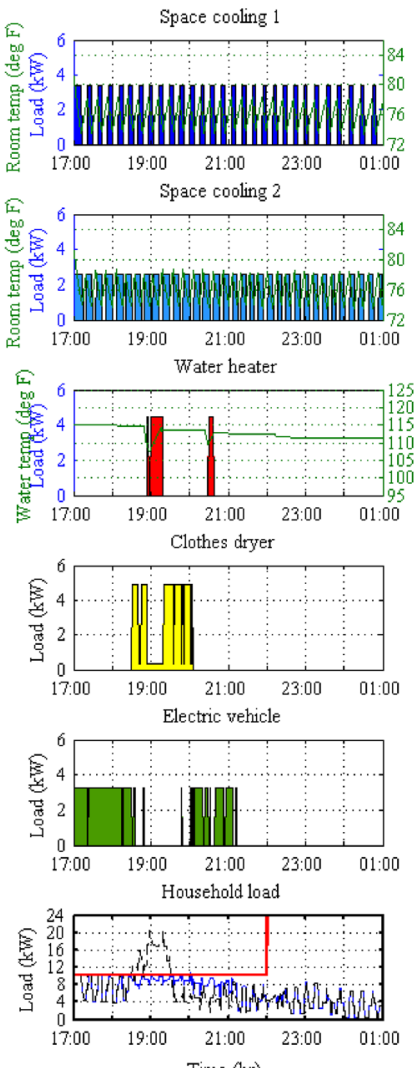

(c) $50 \%$ peak reduction
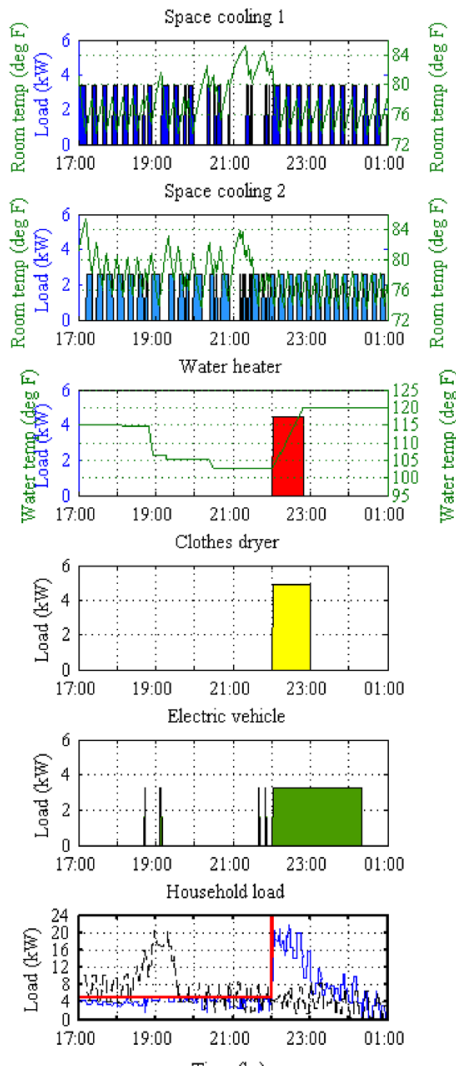

(d) $75 \%$ peak reduction
Fig. 7 Power consumption of individual appliances (AC1, AC2, WH, $\mathrm{CD}$ and EV) and total household load profiles of the 4500 sqft house between 5:00 PM and 1:00 AM: (a) no DR; (b) w/DR at 25\% load

As can be seen in Table 5, there is no violation in room temperature in the 1500 sqft house even with a $75 \%$ peak demand reduction request. The level of room temperature curtailment request; (c) w/DR at $50 \%$ load curtailment request; and (d) w/DR at $75 \%$ load curtailment request

violation for the 2500 sqft house is also lower than that of the 4500 sqft house. This is due to lower appliances' power ratings in smaller house sizes. 
Observation 2 A bigger house (house with higher appliance ratings, higher number of appliances and higher number of occupants) appears to be more sensitive to a higher load curtailment request.

For example, at $75 \%$ peak demand reduction, customers in a 4500 sqft house may experience higher overall comfort level violation and longer load compensation period than those in smaller houses. As shown in Fig. 7, at 75\% peak reduction, the temperature violation starts from 7:00 PM to 10:00 PM for both AC. This is mainly because of a greater number of electrical appliances with higher ratings in a bigger house.

Observation 3 A bigger house tends to have higher ability to reduce its peak demand during a DR event than a smaller one.

While a bigger house may be more sensitive to DR implementation than a smaller house, the higher amount of electrical demand $(\mathrm{kW})$ can be shifted in a bigger house. For example, at $50 \%$ reduction request, the 1500 sqft house can shed $6.5 \mathrm{~kW}$; the 2500 sqft house can reduce the peak demand by $8.1 \mathrm{~kW}$; and the $4500 \mathrm{sqft}$ house can reduce its peak load $10.3 \mathrm{~kW}$. This is mainly because a bigger house has appliances with higher ratings than those in a smaller house.

Observation 4 For houses of all sizes, it is not always the case that lower-priority loads will have to be deferred more during a DR event. A lower-priority load can gain its priority over a higher-priority one depending on power ratings of appliances in relative to each other and a DR limit request.

For the case of the 2500 sqft house with the $25 \%$ peak demand reduction request, although the EV has lower priority than the $\mathrm{CD}$; the EV can operate with WH during the DR event, while the $\mathrm{CD}$ is always deferred, thus resulting in lower total EV compensation time as shown in Table 5. This is because the rating of $\mathrm{CD}(4 \mathrm{~kW})$ is higher than that of $\mathrm{EV}$ ( $3.3 \mathrm{~kW}$ ), which prevents CD to operate with $\mathrm{WH}$ during the DR event; while the EV, although it has the lowest priority, can operate with WH operation.
Observation 5 A high load curtailment request may result in an adverse effect by creating a new peak during an offpeak period. This may overload a distribution transformer. The transformer overloading level will also depend on the number of houses connecting a distribution transformer.

To elaborate this point, the background related to an electric distribution system in the US is given below. In the area of interest, a survey has been conducted and it is found that: generally, a $25 \mathrm{kVA}$ distribution transformer serves 3-5 small houses; a $50 \mathrm{kVA}$ distribution transformer serves 4-6 medium houses; and a $100 \mathrm{kVA}$ transformer serves 5-7 large houses. For cases presented in Table 5, the $75 \%$ peak load reduction may be acceptable for three 1500 sqft houses of similar consumption characteristics served by a $25 \mathrm{kVA}$ distribution transformer. With the $75 \%$ peak load reduction request for such a case, the transformer loading level can increase to about $28 \mathrm{~kW}(9.3 \mathrm{~kW} \times 3$ or $31 \mathrm{kVA}$ at $0.9 \mathrm{PF})$ after the DR event ends. See Table 5 . This represents $25 \%$ overloading level of this $25 \mathrm{kVA}$ distribution transformer-which is acceptable for a short time during such off-peak periods due to low nighttime ambient temperature, and low transformer loading level prior to the load compensation period. However, if there are more than 3 houses connecting to this transformer, the resulting transformer overloading level may not be acceptable.

Observation 6 The load curtailment amount that results in acceptable customer comfort violation appears to be up to $50 \%$ for houses of all sizes.

According to Table 5, at $25 \%$ load curtailment request, houses of all sizes have no room/water temperature violations. Clothes dryer operation is prolonged for a short duration (i.e., 12 minutes or less). EV charging duration is also extended for a short time, i.e., 3 mins for the $1500 \mathrm{sqft}$ house, and at most 42 mins for the 4500 sqft house.

For customers who can accept longer operation duration of clothes dryers and electric vehicles, $50 \%$ load curtailment request can be achieved with no impact on HVAC operation. However, the hot water temperature violation of a few degrees can be experienced during a DR event.

Table 6 Appliance usage patterns for a 4500 sqft house

\begin{tabular}{|c|c|c|c|c|c|}
\hline Case scenarios & $\mathrm{AC} 1$ operation time & AC2 operation time & Hot water drawn & CD start time & EV start time \\
\hline Case 1 & All day & All day & High & 6:30 PM & 5:00 PM \\
\hline Case 2 & All day & All day & Low & 6:30 PM & 5:00 PM \\
\hline Case 3 & All day & All day & High & 8:30 PM & 5:00 PM \\
\hline Case 4 & All day & All day & Low & 8:30 PM & 5:00 PM \\
\hline Case 5 & All day & All day & - & 6:30 PM & 5:00 PM \\
\hline Case 6 & All day & All day & - & 8:30 PM & 5:00 PM \\
\hline
\end{tabular}




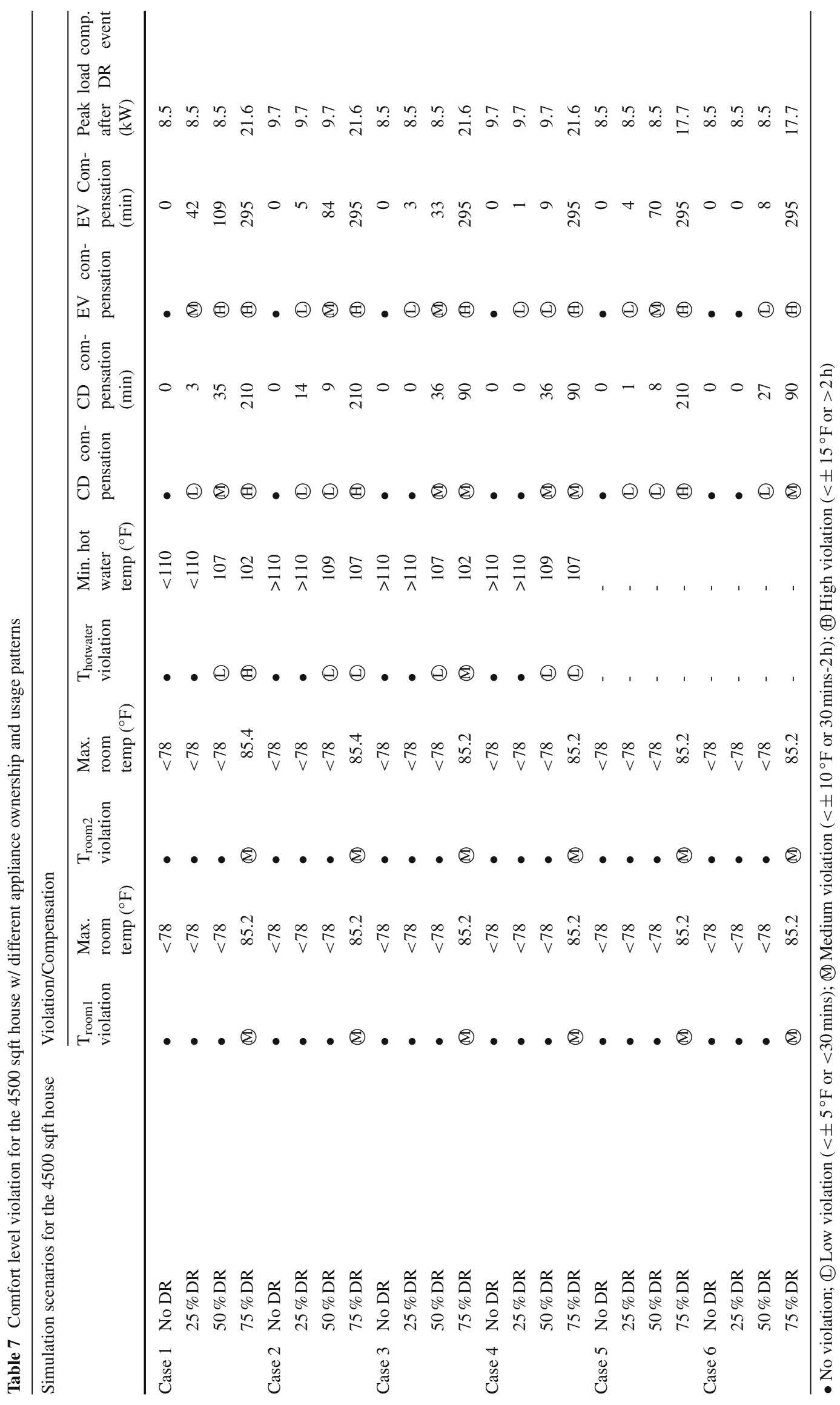




\section{Impact of Usage Patterns on Customer Comfort Level Violation}

The result presented in the previous section shows that the 4500 sqft house has more customer violation and longer load compensation period than houses of smaller sizes. Therefore, these cases are extended in this section to show the impact of usage patterns on the customer comfort level violation. Using the same set of assumptions discussed in Section 3, different usage patterns considered are summarized in Table 6 .

All cases use the same AC and hot water temperature set points. Cases 1 and 3 include a large hot water drawn event; while Cases 2 and 4 have a smaller hot water drawn event at the same time. The CD start time is at 6:30 PM for cases 1,2 and 5; and is at 8:30 PM for cases 3, 4 and 6. The EV start time is at 5:00 PM for all cases. For Cases 5 and 6, it is assumed that the house has gas water heater, i.e., no electric water heater. Table 7 summarizes the impact of usage patterns and appliance ownerships on customer comfort level violation in all simulation scenarios mentioned above.

The following observations can be made from Table 7:

- For all usage patterns shown in the Table above, if the demand curtailment request is not too high, the comfort level violation of the highest priority load may not be experienced. As shown, at 25 and $50 \%$ curtailment requests, there is no room temperature violation experienced for all cases. At $75 \%$ request, violations occur because both ACs cannot operate with a high critical load.

- Lower water usage will result in lower comfort level violation and the load compensation for all appliances having lower priorities than WH-See Cases 2 and 4.

- Shifting the start time of a load may lead to a lower comfort level violation for the loads with lower prioritySee Cases 3, 4 and 6.

- The lowest-priority load shifts before other loads in all cases. This results in comfort level violation, which starts at $25 \%$ reduction for lower-priority loads, except for Case 6 where the comfort level violation starts at $50 \%$ reduction. This is contributed by the use of gas water heater and the usage pattern of the CD that starts at 8:30 PM.

- Lower comfort level violation and load compensation occur in houses with no electric water heater-See Cases 5 and 6. However, a house without an electric water heater also shows less flexibility to perform DR due to lower power demand $(\mathrm{kW})$ to be shifted.

\section{Conclusion}

This paper aims at studying the relationship between household power consumption and appliance ratings, customer behaviors, house sizes, number of people in a house and type of appliances available using a case-based study. Due to involvement of many parameters including customer preference, this relationship may not always be obvious. The effect of demand limit levels on customers' comfort level violation is also presented. Simulation results show that customer comfort level violation and load compensation are a function of demand limit level, appliance rating, appliance usage pattern, and customer preference. A smaller house tends to offer more flexibility to perform DR than a bigger house; while a bigger house appears to be more sensitive to a high load curtailment request. Also, a bigger house tends to have higher ability to reduce its peak demand during a DR event. In addition, performing a DR implementation with a high load curtailment request may lead to high load compensation after a DR event ends, unless a preventive measure is implemented. This can be a topic of future research when designing a home energy management (HEM) algorithm.

Results of this work give an insight into an auto-DR implementation for residential customers of different characteristics (house sizes, appliance ratings, usage patterns). This set of understandings serves as the first step to the design of appropriate DR programs and HEM systems by academia/industry researchers.

\section{References}

1. DOE-EIA, Energy Efficiency and Renewable Energy. International Energy Outlook (2011). [Online]. Available: http://205.254.135. 24/forecasts/ieo/pdf/0484(2011).pdf

2. Albadi, M., El-Saadany, E.: Demand response in electricity markets: an overview. In: IEEE Power Engineering Society General Meeting, 2007, 24-28 June 2007, pp. 1-5

3. Faria, P., Vale, Z.A., Ferreira, J.: Demsi-A Demand Response Simulator in the Context of Intensive Use of Distributed Generation. In: Proceedings of IEEE Systems Man and Cybernetics (SMC), Conference 2010, pp. 2025-2032

4. U.S. Department of Energy, Benefit of Demand Response in Electricity Markets and Recommendations for Achieving Them, February 2006 [Online]. Available: http://eetd.lbl.gov/ea/ems/reports/ congress-1252d.pdf

5. Piette, M.A., Watson, D., Motegi, N., Kiliccote, S., Linkugel, E.: Automated demand response strategies and commissioning commercial building controls. In: 14th National Conference on Building Commissioning, San Francisco, Apr 2006

6. Kumar Nunna, H.S.V.S., Battula, S., Sesetti, A., Doolla, S.: Impact of incentive mechanism on demand response programs in smart microgrids with electric vehicles. Intell. Ind. Syst. 1(3), 245-254 (2015)

7. Ferruzzi, G., Graditi, G., Rossi, F., Russo, A.: Optimal operation of a residential microgrid: the role of demand side management. Intell. Ind. Syst. 1(1), 61-82 (2015)

8. Pedrasa, M.A.A., Spooner, T.D., MacGill, I.F.: Coordinated scheduling of residential distributed energy resources to optimize smart

9. Mohsenian-Rad, A.H., Leon-Garcia, A.: Optimal residential load control with price prediction in real-time electricity pricing environments. IEEE Trans. Smart Grid 1, 120-133 (2010) 
10. Du, P., Lu, N.: Appliance commitment for household load scheduling. IEEE Trans. Smart Grid 2, 411-419 (2011)

11. Son, Y., Pulkkinen, T., Moon, K.D., Kim, C.: Home energy management system based on power line communication. IEEE Trans. Consum. Electron. 56(3), 1380 (2010)

12. Han, J., Choi, C.S., Lee, I.: More efficient home energy management system based on ZigBee communication and infrared remote controls. In: Proceedings of 29th IEEE International Conference on Consumer Electronics (ICCE) (2011)

13. Len, C.H., Bai, Y.W., Chen, H.C., Hung, C.H.: Home appliance energy monitoring and controlling based on power line communication. In: Proceedings of the 27th IEEE International Conference on Consumer Electronics (ICCE) (2009)

14. Li, J., Chung, J.Y., Xiao, J., Hong, J.W.K., Boutaba, R.: On the design and implementation of a home energy management system. In: Proceedings of the 6th IEEE International Symposium on Wireless and Pervasive Computing (ISWPC) (2011)

15. Han, J., Choi, C.S., Park, W.K., Lee, I.: Green home energy management system through comparison of energy usage between the same kinds of home appliances. In: Proceedings of the 15th IEEE International Symposium on Consumer Electronics (ISCE) (2011), pp. 1-4
16. Pipattanasomporn, M., Kuzlu, M., Rahman, S.: An algorithm for intelligent home energy management and demand response analysis. IEEE Trans. Smart Grid 3, 2166-2173 (2012)

17. Kuzlu, M.: Score-based intelligent home energy management (HEM) algorithm for demand response applications and impact of HEM operation on customer comfort. IET Gener. Trans. Distrib. 9(7), 627-635 (2015)

18. My Chevy Volt. [Online]. Available: www.mychevroletvolt.com

19. National Climatic Data Center [Online]. Available: ftp://ftp.ncdc. noaa.gov/pub/data/asos-onemin

20. Domestic Hot Water Profiles [Online]. Available: http://www. ecbcs.rg/annexes/annex42.htm

21. TED 5000 Energy Monitor. [Online]. Available: http://www. theenergydetective.com 